\title{
TransFormar LA EDUCACIÓN RELIGIOSA EN CLAVE DE ACOGIDA E INTEGRACIÓN DE LA DIFERENCIA
}

\author{
TRANSFORMING RELIGIOUS EDUCATION INTO A KEY TO \\ WELCOMING AND INTEGRATING DIFFERENCE
}

\author{
Karina Ramos Zapata ${ }^{1}$ \\ Santiago, Chile
}

\section{RESUMEN}

En medio de las transformaciones culturales propias de sociedades globalizadas, la religión emerge como un espacio social particularmente relevante a la hora de impulsar procesos que faciliten la integración de la diversidad. Los estudios sociológicos que vinculan la migración con la religión podrían entregar pistas claves para la renovación de los modelos de educación religiosa escolar que rompan con lógicas hegemónicas y permitan la integración en el aula de las diversas experiencias religiosas. En este texto se quiere contribuir a la reflexión acerca de la educación religiosa y sus aportes formativos en el nuevo contexto plural que la rodea.

\section{Palabras Clave}

Migración, educación religiosa escolar, pluralismo, diálogo, transnacionalización.

1 karina.ramoszapata@gmail.com

\begin{abstract}
In the midst of the cultural transformations of globalized societies, religion emerges as a particularly relevant social space in promoting processes that facilitate the integration of diversity. Sociological studies, which link migration to religion, could provide key clues to the renewal of school religious education models that break with hegemonic logics, and allow the integration into the classroom of various Religious experiences. This text wants to contribute to the reflection on religious education and its formative contributions in the new plural context that surrounds it.
\end{abstract}

\section{KEY WORDS}

Migration, school religious education, pluralism, dialogue, Transnationalization. 
Karina Ramos Zapata | Transformar la educación Religiosa en Clave de ACOGIDA E INTEGRACIÓN DE LA DIFERENCIA

\section{UNA MIRADA AL FENÓMENO RELIGIOSO EN LA SOCIEDAD GLOBAL}

A lo largo del tiempo, el desafío de hacer clases de Religión se ha vuelto particularmente complejo. A las dificultades propias de un sistema educativo que agobia tanto a docentes como a estudiantes se suma una baja generalizada en la adhesión y participación religiosa, la profundización de las tendencias a la desinstitucionalización de la fe y las grandes tensiones sociales por privatizar lo religioso; todos estos procesos ponen en tela de juicio el valor de la clase de Religión y su verdadero aporte a la educación pública y privada.

Esto ocurre en un contexto de globalización que ha impulsado transformaciones no solo en las formas de comercio, sino que también deshace progresivamente las murallas culturales y simbólicas, universalizando valores y estilos de vida como consecuencia de la intensificación de las redes comunicativas y de relaciones transnacionales (Beck, 1998), facilitando la superación de las barreras geográficas.

En consecuencia, las sociedades modernas comenzaron a establecer nuevas y profundas relaciones entre países conectados por las trayectorias y esperanzas de los migrantes, quienes, en sus desplazamientos, llevan consigo sus historias, costumbres, tradiciones y formas de ver la vida, las que se territorializan en nuevos contextos, reproduciéndose y transformando los lugares en los que asientan sus vidas (Imilan, Garcés H., \& Margarit S., 2014).

La movilidad internacional, entonces, no puede entenderse como un simple desplazamiento de ida y vuelta, que concluiría con la asimilación de los recién llegados a las costumbres y tradiciones de la sociedad que los acoge, sino más bien, debe mirarse como un proceso dinámico que afecta tanto a las sociedades emisoras de flujos migratorios como a los países receptores, los que se cruzan con las relaciones familiares, económicas, sociales e institucionales que dan paso a nuevos modos de vida, formas de ser y de pertenecer (Stefoni, 2014). De esta manera, los migrantes, así como los nativos de la sociedad receptora, ven cómo sus vidas, sabores y costumbres 
se transforman como parte de la experiencia migratoria (Juárez Cerdi, 2012).

En el caso de Chile, la migración ha crecido sistemáticamente a lo largo de aproximadamente los últimos diez años, convirtiendo al país en un polo de recepción de la migración en Latinoamérica. Según datos del Censo 2017, un 4,35\% de la población que reside en Chile nació en el extranjero, principalmente en Perú, Colombia y Bolivia. Sin embargo, en el último tiempo, han aumentado sistemáticamente los flujos que provienen desde Haití y Venezuela²

Esta creciente ola migratoria llega a asentarse a un país que no estaba preparado para el explosivo incremento de la población migrante. Por una parte, porque la normativa chilena no contemplaba una política migratoria que permitiera la aplicación de políticas públicas eficientes para gestionar y administrar a la nueva población; por otra, porque la ley migratoria vigente tomó forma durante la dictadura militar; se encuentra fundamentada en el principio de seguridad nacional y establece, por tanto, una serie de criterios que dificultan la obtención de visas temporales y definitivas, produciendo y reproduciendo procesos de exclusión y vulneración de derechos sociales (Stefoni, Ley política migratoria en Chile. La ambivalencia en la comprensión del migrante, 2011).

Estas dificultades en la regularización de la situación migratoria ponen a estos nuevos colectivos en condiciones de exclusión y desigualdad, que tensionan sus proyectos vitales y vulneran sus derechos. Las repercusiones inmediatas pueden observarse en la complicación de los procesos de inserción en los nuevos territorios, ya que, junto con resolver el problema de la regularización de su vida en la nueva sociedad, en muchos casos se ven obligados a adquirir un nuevo idioma y adoptar la nueva cultura en la que se ven inmersos (Hirschman, 2006).

2 Datos extraídos del Departamento de Extranjería y Migraciones de Chile. 
Karina Ramos Zapata | Transformar la educación Religiosa en Clave de ACOGIDA E INTEGRACIÓN DE LA DIFERENCIA

Todas estas tensiones provocan en la población migrante sensaciones de desorientación e incerteza que la impulsa a buscar espacios seguros desde los cuales anclar sus decisiones (Mol, 1971). En esta situación, la religión se convierte en un eje fundamental para dialogar con los nuevos territorios (Yang \& Ebaugh, 2001), puesto que ofrece a los migrantes un lugar conocido que permite la reconstrucción de los vínculos y patrones sociales perdidos en el proceso de desplazamiento territorial.

La experiencia religiosa emerge entonces como un espacio comunitario que proporciona soporte espiritual, aunque también material (Connor, 2008), y juega un papel de guía para los migrantes, quienes obtienen en este lugar una herramienta efectiva que los ayuda a superar los desafíos que supone la integración en el nuevo contexto (Hirschman, 2006).

De este modo, las prácticas religiosas, los rituales y las formas de ser creyente cobran una renovada importancia para la vida de los migrantes. Practicar una religión ya no se reduce solo a una experiencia de comunicación con Dios y lo divino, pues también implica una forma de vincularse con la comunidad de personas que los reciben en el nuevo territorio y, al mismo tiempo, les permite reproducir comportamientos y ritos identitarios de sus lugares de origen: cantar, rezar y celebrar será la manera más común en que estos colectivos se conectarán con los hogares y personas dejadas al comenzar el viaje.

Así, poco a poco, las tradiciones religiosas de migrantes y nativos van entrando en contacto, tensionándose, adaptándose y enriqueciéndose con los aportes de quienes las practican. De esta forma, la religión va conectando trayectorias globales y produciendo nuevas expresiones religiosas locales propias de una religión multicentrada ${ }^{3}$ (Levitt, 2007).

Otra de las consecuencias de los procesos de migración en el ámbito religioso es el crecimiento en la diversidad religiosa de los territorios

3 Se trata de religiones que, como consecuencia de la globalización, se desplazan de los centros culturales en los que fueron constituidas hacia nuevas localidades, dando forma a nuevos centros religiosos, con interpretaciones y prácticas religiosas regionalizadas y en constante comunicación con otros centros dentro del globo. 
de recepción. La diversidad cultural presenta un desafío para las instituciones religiosas hegemónicas (Casanova, La inmigración y el nuevo pluralismo religioso: una comparación Unión Europea/Estados Unidos, 2007); estas tendrán que convivir con nuevas adhesiones y formas de comprender el fenómeno religioso que le abren nuevas condiciones de posibilidad y provocan una pérdida del carácter homogéneo de los modelos religiosos monoconfesionales, puesto que ahora comienzan a ser una de las muchas tradiciones y opciones entre las que se puede escoger. En este contexto, la religión se vuelve una opción personal, menos certera y más vulnerable (Berger, Pluralismo global y religión, 2005).

En medio de estas transformaciones culturales, las escuelas -una de las primeras instituciones receptoras de la diversidad presente en la sociedad- se encuentran con un nuevo desafío: acoger la novedad del pluralismo cultural y religioso dentro de las aulas, renovando metodologías y contenidos tradicionalmente proyectados desde perspectivas que suponen la homogeneidad de los miembros de una comunidad educativa, sin marginar las experiencias que se encuentran en las periferias de la cultura dominante.

Particularmente, la clase de Religión tiene aquí un doble desafío: por una parte, acoger nuevas expresiones religiosas, muchas veces lejanas a la tradición cristiano-occidental y de vertiente romana (hegemónica en Chile); y, por otra, asumir el papel primordial que la religión tiene en la inserción de los recién llegados, generando espacios educativos adecuados para la resignificación de las experiencias de violencia, discriminación e incertidumbre que caracterizan la llegada de población extranjera a las nuevas sociedades.

¿Se encuentran los docentes encargados de la educación religiosa preparados para acoger esta diversidad? ¿Qué cambios tendrían que considerarse en los planes y programas definidos en esta asignatura para que la educación pudiera acoger esta diversidad presente en los territorios? ¿Qué aporta la integración de las experiencias de los y las migrantes a la educación religiosa escolar? Estas preguntas plantean desafíos para quienes se encargan de la educación religiosa 
Karina Ramos Zapata | Transformar la educación religiosa en clave de ACOGIDA E INTEGRACIÓN DE LA DIFERENCIA

escolar, no solo porque es parte de su labor docente acoger en el aula la diversidad de experiencias presentes en ella, sino también porque la religión puede contribuir de manera significativa a aliviar las experiencias de maltrato y exclusión que tantas personas viven en los procesos migratorios.

En el presente artículo se abordará la cuestión de los modelos de educación religiosa siguiendo el método de la investigación documental, que permite construir conocimientos a partir de la recolección, indagación, organización y análisis de información, y datos relacionados con un tema (Morales, 2003). Esta técnica permitirá presentar una caracterización de los contextos en que emergen los distintos modelos de educación religiosa, y las cualidades y limitantes de cada modelo a la hora de integrar la diversidad de experiencias religiosas que habitan los territorios globales. De esta forma, se busca aportar nuevos aspectos para el análisis del beneficio que supone mantener la clase de Religión en la escuela pública y privada.

\section{ROMPER CON LA EDUCACIÓN RELIGIOSA HOMOGENEIZADA Y HOMOGENEIZANTE}

Para comenzar a responder las interrogantes antes formuladas es necesario considerar el surgimiento de los modelos de educación religiosa escolar. Estos tendieron originalmente al desarrollo de programas de educación monoconfesionales, en los que se priorizó la enseñanza de la religión mayoritaria de una nación; nacieron asociados principalmente a las intenciones de los recién constituidos Estados-nación de afianzar una cierta identidad nacional basada en principios de homogeneidad cultural y territorial (Dietz, 2008).

En Chile, el Decreto Supremo emitido en $1977^{4}$ que reglamentó las clases de Religión, señalaba:

4 Este decreto fue emitido durante la dictadura militar (1973-1990). 
"Que la persona humana tiene una dimensión espiritual que informa su existencia; que la educación tiene como uno de sus objetivos fundamentales alcanzar el desarrollo del hombre en plenitud; (y) que los principios que inspiran las líneas de acción del actual Gobierno descansan en una escala de valores morales y espirituales propios de nuestra tradición chilena y cristiana”. (Decreto No 776 de Educación, de 14 de octubre de 1977).

El mismo Decreto, en su artículo 4, declaraba que las clases de Religión serían impartidas según programas referidos al Magisterio de la Iglesia Católica Romana. Esta perspectiva supuso el desarrollo de programas que acentuaban una homogeneidad teológica y religiosa, privilegiando el monopolio de los contenidos doctrinales y morales que emergen del cristianismo (Panotto, 2019), planteándose como objetivo el logro de un asimilacionismo uniformador (Comboni Salinas \& Juárez Nuñez, 2013) de las experiencias religiosas de quienes se educan en la escuela.

Sin embargo, en 1983 se publicó un nuevo reglamento para esta asignatura, el que incluía una diferencia importante con el anterior, puesto que reemplaza la referencia a la "tradición chilena y cristiana" por "nuestra tradición cultural humanista occidental". Esto dio pie al surgimiento de modelos pluriconfesionales; el Ministerio de Educación puede autorizar la enseńanza de otros credos, siempre que los padres/apoderados/tutores expresen de manera escrita esta solicitud, y se cuente en los establecimientos educativos con personal idóneo y con programas debidamente autorizados por la autoridad religiosa y el propio Ministerio de Educación (Núñez Prieto, 2008).

Ninguno de estos modelos para la asignatura incorpora como centro de la planificación la convivencia y el diálogo de las múltiples experiencias religiosas que coexisten en un establecimiento educativo. Más bien, ambos están pensados desde una perspectiva excluyente, pues reúnen en el aula a quienes adhieren a una misma adscripción religiosa y tienen como objetivo asegurar la enseñanza de la doctrina y práctica religiosa de una determinada fe. Así, la escuela pública puede ofrecer múltiples opciones de educación religiosa escolar de 
forma paralela, incorporando otras ofertas formativas a quienes no adscriben a ninguna religión, las que en general se relacionan con la enseñanza cívica o moral de estos estudiantes (Magendzo, 2008).

En la actualidad, estos modelos son insuficientes a la hora de abordar las diferentes formas de pensamiento, cosmovisiones e intereses que comienzan a caracterizar al fenómeno religioso en la modernidad. Muy por el contrario, así presentados, estos modelos podrían ejercer una violencia simbólica 5 al intentar imponer entre los sujetos creyentes una única forma válida de expresión de la religiosidad, universalizando un único discurso, forma de ver el mundo y práctica religiosa aceptada como verdadera.

Avanzar hacia la construcción de modelos de enseñanza religiosa escolar interconfesionales, los cuales evitan la segregación de los estudiantes mediante el respeto de sus diferencias religiosas, tendría un impacto positivo a la hora de educar religiosamente, puesto que promovería entre los educandos el desarrollo de mejores herramientas para enfrentar la vida en una sociedad global y del conocimiento. Al mismo tiempo, facilitaría la incorporación de las problemáticas políticas, sociales y culturales que tienen un impacto directo en la educación religiosa (Magendzo, 2008), toda vez que median en la construcción simbólica que hacen los sujetos religiosos desde su contexto.

5 Hacemos uso del término violencia simbólica, tomado del desarrollo teórico del sociólogo Pierre Bourdieu, para aludir a la violencia que se ejerce a partir del esfuerzo por legitimar y conservar un cierto orden social, el que organiza el mundo a partir de principios de inclusión/exclusión, creando sentidos de pertenencia y asociación entre quienes comparten una misma percepción del orden natural. Esto predispone a distinguir y excluir a los "otros" que no cumplen con los imperativos éticos impuestos como norma general. 


\section{LA GLOBALIZACIÓN DE LA FE Y LA DIVERSIFICACIÓN DE LA PRÁCTICA RELIGIOSA}

Las investigaciones que vinculan los fenómenos religiosos y las migraciones dan cuenta de una intensificación de la dimensión religiosa de los sujetos como consecuencia del viaje migratorio, situación que estaría detrás del aumento de la práctica religiosa entre los recién llegados a una nueva comunidad (Cadge \& Ecklund, 2007). Estos resultados muestran que las religiosidades vinculadas a la migración no decaen, sino, muy por el contrario, conducen a una revitalización de las Iglesias locales, las que se ven obligadas a replantear su ejercicio pastoral para dar respuesta a las necesidades de esta nueva feligresía (Berger, 2004).

Una de las razones que explicaría este fenómeno se encuentra en la función de integración que el campo religioso tendría dentro de las sociedades. La institucionalidad religiosa proporciona un contexto ideal para la resignificación de las experiencias y frustraciones de los sujetos creyentes, al mismo tiempo que les entrega certezas para la vida a partir del precepto religioso. Como resultado, la religión permite la conformación de sistemas simbólicos que dan origen a estructuras que ordenan el mundo y crean sentidos de pertenencia (Bourdieu, 1998).

Así, quienes practican una religión nunca lo hacen de forma individual, sino que están vinculados a un grupo que se cohesiona a consecuencia de una misma forma de concebir la realidad y las relaciones entre el mundo profano y el sagrado (Durkheim, 2012). Estas condiciones del campo religioso proporcionan un espacio para que los migrantes, con determinadas adhesiones religiosas, puedan insertarse fácilmente en comunidades que les permitirán comprender los nuevos patrones de comportamiento social que les son exigidos, mientras logran preservar sus propias identidades étnicas, tanto en forma personal como colectiva.

De esta manera, la experiencia religiosa se transforma en uno de los recursos más importantes de socialización con los que cuentan los 
Karina Ramos Zapata | Transformar la educación Religiosa en Clave de ACOGIDA E INTEGRACIÓN DE LA DIFERENCIA

migrantes, puesto que tiene la particularidad de ser parte de una serie reconocida y aceptada de prácticas en cualquier espacio social, que permite a los colectivos de migrantes integrarlas muy tempranamente en la sociedad que los recibe y, con ellas, reivindicar un aspecto de su identidad particular (Juárez Cerdi, 2012). Al mismo tiempo, les entrega herramientas para establecer una continuidad en sus formas de ser y pertenecer a una comunidad que se encuentra fuera de su sociedad de origen.

Sin embargo, esta continuidad no implica necesariamente un trasplante de las prácticas religiosas de un territorio a otro; por el contrario, estas prácticas se ven expuestas a procesos de transformación, que permitirán a quienes comparten una misma fe crear puentes simbólicos y acceder a una comunidad de iguales que facilitan la socialización y la cohesión social.

En el marco de una sociedad globalizada, este proceso podría ser muy positivo. La intensificación de las redes transnacionales ha permitido el desarrollo de una cultura global, en la que diferentes expresiones culturales se encuentran con un marco común para la generación y adaptación de prácticas y representaciones sociales, que viajan de un contexto a otro sin problemas, modificando las pautas de vida cotidiana entre quienes se encuentran conviviendo en un mismo territorio (McLuhan \& Powers, 1996).

Sin embargo, que las nuevas sociedades comiencen a estar conformadas por un mosaico de culturas diversificadas que conviven en un mismo espacio no supone necesariamente que los sujetos vivan también pluralmente. Muchas veces, este marco cultural tiende también a generar la uniformidad de los sujetos que lo habitan, sometiendo a las culturas subalternas a participar obligadamente de las formas de vida "oficiales"; desplazando, silenciando e invisibilizando las particularidades étnicas de las culturas minoritarias de un territorio, y haciendo de estas una expresión folclórica o barbárica que debe ser eliminada (Comboni Salinas \& Juárez Nuñez, 2013).

En esta situación, algunos colectivos de migrantes se ven obligados a asimilar formas de vida no elegidas para no quedar doblemente 
marginados de la sociedad. En el caso de la práctica religiosa, todas aquellas expresiones de fe que se encuentren fuera de las aceptadas hegemónicamente podrían transformarse en un obstáculo para la integración de los colectivos y, en consecuencia, ser excluidas del repertorio habitual, aunque muchas veces formen parte de profundos sistemas de cognición y expresión comunitaria característicos de una identidad particular.

Esta realidad se ve reflejada en la escuela, donde conviven diversas expresiones culturales y comprensiones de lo religioso que tensionan las construcciones sobre la norma tradicional hegemónica y, a la vez, exigen hacerse cargo de las relaciones de poder en el ámbito de las interacciones culturales, incorporando nuevas perspectivas que superen el simple desarrollo de la tolerancia para la convivencia y se enfoquen en dar respuestas a las demandas por autonomía que las culturas subalternas exigen para reivindicar la plena validez de su propia identidad.

En el caso de la educación religiosa escolar, los modelos educativos dominantes no se encuentran preparados para administrar la diversidad de miradas religiosas, puesto que están desarrollados con el fin de dar una única respuesta válida a las preguntas por lo sagrado y la trascendencia, con exclusión de las identidades culturales y religiosas minoritarias, incidiendo así en la aparición de fundamentalismos doctrinales que podrían alimentar conflictos político-sociales, al mismo tiempo que predispondrían al desarrollo de inseguridades personales entre quienes pertenecen a estas comunidades excluidas.

Por otro lado, los modelos de educación mono y pluriconfesionales anteriormente presentados se encontrarían poco preparados para responder a las preguntas por el sentido que emergen en sociedades fragmentadas (Magendzo, 2008). Al no dialogar con la diversidad, la educación religiosa escolar actual ofrece a los estudiantes respuestas reduccionistas del fenómeno religioso, dificultando el diálogo entre culturas diferentes y provocando la marginación, en el espacio de lo privado, de las prácticas y comprensiones religiosas estimadas como exóticas (Panotto, 2019). 
Karina Ramos Zapata | Transformar la educación religiosa en clave de ACOGIDA E INTEGRACIÓN DE LA DIFERENCIA

Debemos considerar que, tanto la asignatura Religión que se imparte en la escuela como la formación teológica de los docentes encargados de impartirla, monopolizan las comprensiones cristianooccidentales y los desarrollos teóricos eurocéntricos tanto respecto de los contenidos propios de la filosofía como de los de la teología; lo que también estaría limitando la capacidad de integrar, en los modelos de educación religiosa, experiencias y desarrollos conceptuales que emergen de culturas que se encuentran fuera del eje que define las comprensiones actuales del fenómeno religioso.

Entonces, es necesario que se logre reivindicar el conocimiento teológico desde su perspectiva heterodoxa y, de esta forma, integrar en nuestra educación religiosa escolar sentidos y cosmovisiones construidos desde núcleos de elementos simbólicos, rituales y relacionales que emergen desde la periferia del saber religioso eurocéntrico. Una vez alejados del absolutismo conceptual, será posible dar voz a las experiencias religiosas que hoy se encuentran marginadas de la escuela.

Incluir perspectivas pluralistas a la hora de planificar la asignatura de Religión permitirá a los estudiantes encontrar las respuestas de sentido a partir de un profundo diálogo de fe en medio del aula, y exigirá a los docentes dar cuenta de la pluralidad de la expresión religiosa presente en ella. Esto enriquecerá la comprensión del fenómeno religioso y promoverá el desarrollo de competencias útiles para el desarrollo de análisis críticos de la realidad, mejorando el diálogo de la fe con la vida cotidiana, que es fundamental para el aprendizaje significativo de los contenidos religiosos.

La incorporación de saberes transfronterizos en el área de la religión permitirá también agregar como recurso educativo la experiencia teológica de las comunidades de migrantes, que en la actualidad solo es visibilizada desde una perspectiva folclorizada. Esta validación de la identidad migrante no solo contribuirá a facilitar los procesos de integración, sino que también permitirá a los nativos interesarse por el conocimiento del "otro" desde posicionamientos desprejuiciados, lo que tendría como consecuencia la disminución de las situaciones 
de discriminación y marginación racial cada vez más comunes en las sociedades modernas.

\section{TRANSNACIONALIZAR LA EDUCACIÓN RELIGIOSA}

Una de las dificultades más comunes a la que se ven enfrentados los colectivos de migrantes es la expectativa de asimilación que plantea la sociedad receptora. Estas expectativas están asociadas con la comprensión de la migración como un proceso unidireccional (Pries, 1999), el que se da solo una o dos veces en la vida de un sujeto, y que concluiría con su regreso a la sociedad de origen, o con la "correcta inserción" del individuo en la nueva sociedad.

El punto final de esta fase de inserción estaría caracterizado por la eliminación de los diversos orígenes culturales dentro del marco común de la cultura dominante, proceso que descartaría la heterogeneidad al ver subsumidas las diferencias frente a la pertenencia a una misma nación ${ }^{6}$. Por esta razón, quienes asumen esta perspectiva teórica esperan que, de alguna manera, los migrantes abandonen completamente su sociedad de origen, viéndose absorbidos por la nueva cultura que los rodea.

Sin embargo, la experiencia migratoria se encuentra muy lejana de esta descripción. La globalización facilita que quienes migran logren mantener profundas relaciones familiares, sociales, institucionales e incluso económicas con sus sociedades de origen. Por tanto, la inserción en los nuevos territorios no implicaría un abandono de las identidades étnicas, sino más bien supondría el desarrollo de procesos de transformación en los sentidos de pertenencia, a partir de una seguidilla de tensiones y negociaciones desde los cuales emergen nuevos modos de ser y pertenecer.

6 A esta expectativa las teorías sobre la migración le llamó enfoque asimilacionista (Stefoni, 2014; Berganza, 2017; Jensen, 2014). 
Karina Ramos Zapata | Transformar la educación religiosa en clave de ACOGIDA E INTEGRACIÓN DE LA DIFERENCIA

Este enfoque, llamado "de redes" por las teorías de la migración, permite dar particular importancia a la construcción de espacios sociales que trascienden, a la vez que incorporan, lo local, mediante procesos de desterritorialización y reterritorialización de las vidas migrantes, creando un tercer espacio social transfronterizo, en el que se vive de manera simultánea aquí y allá (Stefoni, 2014; Imilan, Garcés H., \& Margarit S., 2014).

Asumir esta comprensión permite incorporar claves relevantes a la hora de pensar nuevos modelos para la educación religiosa escolar. Por una parte, es necesario considerar que en el ámbito de la migración se trata tanto de quienes migran como de quienes se quedan en las sociedades de origen. Quienes deciden emprender un viaje migratorio lo hacen como parte de una esperanza que incorpora a toda una red de personas que no necesariamente se desplazan junto a ellos.

Las redes que conectan a ambas sociedades construyen nuevos lazos que se amplían, fortifican, transforman y dan origen a nuevas formas de participación, las que superan fronteras nacionales y permean la vida cotidiana de quienes participan en ellas. Estos lazos suelen darse al alero de grupos religiosos, sociales o políticos a los que pertenecen y que también comienzan a operar por encima de las fronteras (Levitt, 2007).

Por otra parte, estas redes van a facilitar la eliminación de las limitantes territoriales que restringían el desarrollo cultural local. Como parte del proceso de transnacionalización, estas referencias comenzarán a desconectarse de los territorios nacionales y darán pie a la formulación de sistemas globales que dotarán de sentido al contexto social. Estos sistemas tendrían fuerte influencia en la diversificación de las opciones de posibilidad en la vida de los sujetos que participan en ellas, al moldear nuevas ideas acerca de normas universales vinculadas a los derechos humanos, la justicia social, las estructuras políticas y económicas, entre otros aspectos del contexto en el que se encuentran inmersos.

Estos cambios recorrerán las redes trasnacionales, aportando diversas comprensiones de los fenómenos sociales. Cruzarán las 
fronteras y tensionarán las ideas que, hasta ahora, eran aceptadas como las únicas explicaciones posibles. Frente a esta situación brotarán dos tipos de respuesta: una de naturaleza conservadora, la que frente a la amenaza que supone la aparición de nuevas identidades exacerba las respuestas localistas; y otra de carácter pluralista, que se alimenta de estas nuevas comprensiones, ayudando a la emergencia de respuestas globales que incorporan los valores propios de la cultura emergente (Levitt, 2007).

Las implicancias de esta situación afectarán de manera directa el desarrollo de los procesos educativos, puesto que ellos canalizarán las diversas ideas que circulan como parte de las nuevas redes de relaciones transnacionales. La escuela será una de las primeras instituciones que tendrá que hacerse cargo de los efectos de las transformaciones culturales y relacionales que forman parte de la cultura global, por lo que deberá asumir la importante responsabilidad de moldear, a partir de los procesos educativos, las respuestas de los sujetos a la hora de enfrentarse a la convivencia con lo diferente.

La ya mencionada centralidad que tiene la religión en la vida de los migrantes situará a la educación religiosa escolar en la vanguardia del desarrollo de modalidades que propicien la integración de la diversidad en el aula. A quienes se encuentran liderando estos procesos, les exigirá la elaboración de respuestas eficaces que logren resolver la tensión entre lo global y lo local.

En este contexto, se hace necesario construir nuevos modelos de educación religiosa escolar, esta vez desde una perspectiva transnacional, los que aprovechen la oportunidad de estructurar respuestas sólidas, que logren recomponer el entramado de la convivencia social utilizando de manera estratégica la centralidad que tiene la experiencia religiosa entre las comunidades de migrantes (Santos Rego, 2017).

Será en el seno de esta modalidad de educación religiosa escolar donde se podrá ensayar nuevas formas de aproximación a la realidad que sean respetuosas de las identidades y creencias heredadas, al mismo tiempo que permitan la mantención de la cohesión social entre quienes provienen de contextos radicalmente diferentes. Para 
Karina Ramos Zapata | Transformar la educación Religiosa en Clave de ACOGIDA E INTEGRACIÓN DE LA DIFERENCIA

lograrlo, es necesario que los educadores se entiendan a sí mismos como la primera cara de la integración, planificando intervenciones pedagógicas que privilegien el diálogo en la consecución de sus objetivos pedagógicos.

Se trata de construir una educación religiosa escolar que ayude en el cruce entre las tradiciones y creencias diversas que habitan el contexto escolar, invitando a contrastar las bases filosóficas y teológicas que las originan (Santos Rego, 2017). Para implementar esta nueva modalidad de enseñanza, será fundamental que los educadores se focalicen pedagógicamente en el desarrollo de habilidades del pensamiento crítico que permitan a los estudiantes, tanto nativos como inmigrantes, valorar las contribuciones culturales que las diversas expresiones hacen tanto en el campo religioso como en el espacio público.

Hoy, como nunca, se hace necesaria una asignatura de Religión que consiga abordar el conocimiento religioso de manera convocante, que logre cuestionar y cuestionarse los saberes hegemónicos con el objetivo de incorporar las nuevas sensibilidades religiosas, poniendo en el centro de la misma a hombres y mujeres en su búsqueda por la verdad y su lugar en el mundo.

En consecuencia, es necesario abordar estos procesos pedagógicos a partir de la contemplación del fenómeno religioso en su plenitud, alejándose, por una parte, de simplificaciones que reducen este conocimiento a su dimensión informativa o moral; promoviendo, por otra, modelos de educación interconfesionales que inviten a sus protagonistas a aproximarse a la realidad de un modo particular: el de una fe que dialoga y que valora la heterogeneidad no tolerándola como una diversidad pasiva (Panotto, 2019), sino como una herramienta para la construcción de conocimientos teológicos glocales ${ }^{7}$ que amplíen las comprensiones acerca de lo sagrado.

7 Entendemos por glocal al proceso de construcción de la red transnacional de representaciones sociales y orientaciones de acción globales que, compartidas y sintetizadas por las y los actores locales, generan nuevas construcciones de sentido (Mato, 2001). 


\section{Conclusiones}

Es importante volver a subrayar el aporte fundamental que la religión hace a la integración de las diversas experiencias creyentes que aparecen de la mano con la migración. En la actualidad, son las instituciones religiosas las que se encuentran liderando los procesos de protección, defensa e integración social de los colectivos de migrantes, subvencionando un proceso que hasta ahora estuvo abandonado por el Estado.

Las redes que se han desarrollado desde estas experiencias se transforman en herramientas que es necesario considerar en la creación de las políticas públicas que tiendan a la acogida de estos flujos migratorios.

Al mismo tiempo, la vinculación entre la religión y los procesos de integración de las comunidades de migrantes ha planteado un desafío tanto a las sociedades modernas como a la institucionalidad religiosa: superar la visión secular que entiende que los componentes religiosos deben ser eliminados de la esfera social, aceptando que no todas las dimensiones de lo religioso son incompatibles con el espacio público.

El establecimiento de un vínculo virtuoso entre las instituciones educativas y las religiosas podría permitir que la educación religiosa se transforme en un eje orientador de las políticas públicas destinadas a la gestión de la diversidad cultural. Para conseguirlo será necesario, por una parte, reconocer la importancia de no borrar la educación religiosa escolar del mapa curricular; por otra, se vuelve imprescindible que quienes se encuentran detrás del desarrollo de los modelos pedagógicos de la asignatura de Religión sepan articular y hacer dialogar sus objetivos educativos con propósitos sociales de integración, particularmente cuando se habla de la educación pública.

En el caso de la escuela privada, si bien esta puede desarrollar propuestas educativas orientadas a fortalecer sus identidades particulares, no es posible que ella avance de manera plena sin considerar los factores sociales que la impactan. Una educación 
Karina Ramos Zapata | Transformar la educación religiosa en clave de ACOGIDA E INTEGRACIÓN DE LA DIFERENCIA

religiosa que no integre las concepciones de un Dios transnacional, que supera las limitaciones geográficas a la hora de dar respuestas por el sentido, se transformará en un obstáculo para la relación de sus estudiantes con el fenómeno religioso, limitando su experiencia a un campo particular que renuncia a enriquecerse a través del diálogo y la integración de lo diverso.

Asimismo, la Iglesia, mediante la Congregación para la Educación Católica (2013), reconoce el desafío que supone el levantamiento de modelos de educación intercultural, asumiendo que es parte de la naturaleza de la educación ser abierta y evitar la conformación de enclaves culturales. Esta apropiación de la necesidad de contar con espacios escolares que permitan un intercambio dinámico, que ayude a comprender las diferencias y las convierta en motivo de enriquecimiento mutuo (Congregación, 2013) será un factor decisivo que facilite la transformación de las clases de Religión en la actualidad.

Por último, a lo largo de esta reflexión se hace evidente la necesidad de renovar la formación de los docentes de Religión, esta vez desde una perspectiva teológica en clave de diálogo interreligioso. No será posible desarrollar nuevos modelos educativos que logren hacerse cargo de las condiciones desafiantes que rodean la asignatura Religión sin educadores debidamente preparados para el desarrollo de didácticas que integren conocimientos heterodoxos e intencionen un diálogo constructivo entre las diversas experiencias religiosas. Todo esto, sin perder de vista el corazón de la educación religiosa escolar: proporcionar herramientas para que los estudiantes logren desarrollar una espiritualidad que los lleve a transformar sus condiciones de vida material, en la búsqueda de una vida plena con perspectiva de bien común. 


\section{REFERENCIAS BIBLIOGRÁFICAS}

Beck, U. (1998). ¿Qué es la globalización? Falacias del globalismo, respuestas a la globalización. (B. Borrás, Trad.) Barcelona: Paidós.

Berger, P. (2004). Las religiones en la era de la globalización. Iglesia Viva (218), 4-6.

(2005). Pluralismo global y religión. Estudios Públicos. (98), 5-18.

Bourdieu, P. (1998). Capital cultural, escuela y espacio social. (I. Jiménez, Trad.) México: Siglo XXI Editores.

Cadge, W., \& Ecklund, E. (2007). Immigration and Religion. Annual Review of Sociology. (33), 359-379.

Casanova, J. (2004). Religiones públicas en un mundo global. Debate: las religiones en la era de la globalización, 69-92. - (2007). La inmigración y el nuevo pluralismo religioso: una comparación Unión Europea/Estados Unidos. Revista CIDOB d'afers internacionals, 13-39.

Comboni Salinas, S. \& Juárez Nuñez, J. M. (abril de 2013). Las interculturalidad-es, identidad-es y el diálogo de saberes. Reencuentro (66), 10-23.

CONGREGACIÓN PARA LA EDUCACIÓN CATÓLICA (2013). Educar al diálogo intercultural en la escuela católica. Vivirjuntos para una civilización del amor. Ciudad del Vaticano, 28.

Connor, P. (2008). Increase or decrease? The impact of the international migratory event on immigrant religious participation. Journal for the scientific study of religion, 47 (2), 11-44.

Dietz, G. (2008). La educación religiosa en España: ¿Contribución al diálogo intercultural o factor de conflicto entre religiones? Estudios sobre las culturas contemporáneas; Vol. XIV, núm. 28, diciembre. Universidad de Colima, México, pp. 11-46. 
Karina Ramos Zapata | Transformar la educación religiosa en clave de ACOGIDA E INTEGRACIÓN DE LA DIFERENCIA

Durkheim, É. (2012). Las formas elementales de la vida religiosa. El sistema totémico en Australia (y otros escritos sobre religión y conocimiento). (2a edición. ed.). (J. H. Rivas, Trad.) México: Fondo de Cultura Económica.

Hirschman, C. (2006). El papel de la religión en los orígenes de la adaptación de los grupos de inmigrantes en Estados Unidos. (A. Portes, \& J. D. [coords.], edits.) Repensando las migraciones. Nuevas perspectivas teóricas y empiricas, 411-439.

Imilan, W., Garcés H., A. \& Margarit S., D. (2014). Flujos migratorios, redes y etnificaciones urbanas. En W. Imilan, A. G. H. \& D. M. S. (edits.), Poblaciones en movimiento, etnificación de la ciudad, redes e integración. (págs. 11-38). Santiago: Ediciones Alberto Hurtado.

Juárez Cerdi, E. (julio-diciembre de 2012). Ser migrante temporal, méxicano católico en Estados Unidos y Canadá. Revista de Sociedades en Transición, VI (2), 4-21.

Levitt, P. (2007). Rezar por encima de las fronteras: cómo los inmigrantes están cambiando el panorama religioso. Migración $y$ desarrollo (8), 66-88.

Magendzo, A. (2008). Una mirada a la educación religiosa en una perspectiva de una educación religiosa pluralista. En A. Magendzo, Hacia una educación religiosa pluralista. Estudio del diagnóstico de la educación religiosa en Chile y Colombia (págs. 15-42). Santiago, Chile: Universidad de Academia de Humanismo Cristiano.

McLuhan, M., \& Powers, B. (1996). La aldea global. Barcelona: Gedisa.

Mol, J. (1971). Immigrant absorption and religion. International Miration Review, 5(1), 62-71.

Mondaca Rojas, C. \& Gajardo Carvajal, Y. (2015). Interculturalidad, Migrantes y Educación. Diálogo Andino (47), 3-6.

Morales, O. (2003). Fundamentos de la investigación documental y la monografía. Manual para la elaboración de la monografía. Mérida, Venezuela: Universidad de Los Andes. 
Núñez Prieto, I. (2008). La religión en la escuela chilena: entre la inculcación y el pluralismo. 1900-1990. En A. Magendzo, Hacia una educación religiosa pluralista. Estudio diagnóstico de la educación religiosa en Chile y Colombia. (págs. 43-59). Santiago, Chile: Universidad Academia de Humanismo Cristiano.

Panotto, N. (17 de abril de 2019). Educación en clave interreligiosa: conocimiento-otro, identidad y alteridad como marco pedagógico crítico. (N. Panotto, Productor) Recuperado en abril de 2019, de RILEP. Red Interreligiosa Latinoamericana de Educación para la Paz: https://rilep.wordpress.com/2019/04/17/educacion-en-claveinterreligiosa-conocimiento-otro-identidad-y-alteridad-comomarco-pedagogio-critico/

Pries, L. (1999). La migración internacional en tiempos de globalización: varios lugares a la vez. Nueva Sociedad (164), 56-68.

Rodríguez Mancini, S. (2005). Pastoral educativa. Una mirada de fe sobre la tarea escolar. Roma, Italia: Cuadernos MEL 28. Hermanos de las Escuelas Cristianas.

Santos Rego, M. A. (2017). La educación intercultural y el pluralismo religioso: propuestas pedagógicas para el diálogo. Educación XXI, 20(1), 17-35.

Stefoni, C. (2011). Ley política migratoria en Chile. La ambivalencia en la comprensión del migrante. En B. Feldman-Blanco, L. R. Sánchez, C. Stefoni, \& M. I. Martínez (edits.), La construcción social del sujeto migrante en América Latina. Prácticas, representaciones y categorías. (págs. 79-109). Santiago: CLACSO-FLACSOUniversidad Alberto Hurtado.

------- (2014). Perspectiva transnacional en los estudios migratorios. Revisión del concepto y nuevos alcances para la investigación. En W. Imilan, A. G. H. \& D. M. S., Poblaciones en movimiento, etnificación de la ciudad, redes e integración (págs. 41-65). Santiago: Ediciones Universidad Alberto Hurtado. 
Karina Ramos Zapata | Transformar la educación Religiosa en Clave de ACOGIDA E INTEGRACIÓN DE LA DIFERENCIA

Yang, F. \& Ebaugh, R. (2001). Transformations in new immigrant religions and their global implications. American Sociological Review, 66(2), 269-288.

Fecha de recepción: 29 de abril de 2019

Fecha de aceptación: 28 de junio de 2019 